\title{
EXTRAÇÃO DO FÓSFORO NATIVO E DO ADICIONADO AO SOLO COM VÁRIAS SOLUÇÕES *
}

\author{
R. A. Catani ** \\ P. N. NAKAMURA
}

A extração do fósforo nativo e do adicionado a amostras de solos (horizonte Ap) Latosol Roxo (LR), Latosol Vermelho Amarelo, fase arenosa (LVa), Podzolizado Vermelho Amarelo-orto (PV) e Podzolizado LinsMarília, variação Marília ( $\mathrm{Pm} 1)$, com diversas soluções $\left(\mathrm{H}_{2} \mathrm{SO}_{4} 0,05 \mathrm{~N} ; \mathrm{HCl}\right.$ $0,05 \mathrm{~N}+\mathrm{H}_{2} \mathrm{SO}_{4} 0,025 \mathrm{~N} ; \mathrm{H}_{2} \mathrm{SO}_{4} 0,05 \mathrm{~N}+\mathrm{NH}_{4} \mathrm{~F} 0,025 \mathrm{~N} ; \mathrm{e} \mathrm{CH}_{3} \mathrm{COOH}$ $0,10 \mathrm{~N})$, decresceu pronunciadamente ( $50 \%$ ou mais), em muitos casos, quando a relação pêso da amostra (em gramas) para volume (em $\mathrm{ml}$ ) da solução extratora variou de 5:100 para 20:100.

A solução de $\mathrm{H}_{2} \mathrm{SO}_{4} 0,05 \mathrm{~N}+\mathrm{NH}_{4} \mathrm{~F} 0,025 \mathrm{~N}$ extraiu mais fósforo nativo e adicionado ao solo do que as demais soluções nos solos LR, LVa e PV, isto é, solos com um certo teor de sesquióxidos, de $\mathrm{pH}$ baixo, indicando a ação solubilizante do ânion fluoreto, quer pela ação complexante frente ao ferro e alumínio, libertando o fosfato, quer pela troca aniônica ou, ainda, evitando a refixação ou readsorção do fósforo extraido.

A solução de ácido acético $0,10 \mathrm{~N}$ extraiu fósforo nativo e adicionado em quantidade relativamente elevada apenas do solo Pm1, isto é, com $\mathrm{pH}=7,1$, baixo teor em sesquióxidos e teor razoável em $\mathrm{Ca}+\mathrm{Mg}$, onde o fósforo provavelmente tende a integrar sistemas cálcicos. Nos demais solos, com pH baixo e teor de sesquióxidos mais elevado, a solução de $\mathrm{CH}_{3} \mathrm{COOH} 0,10 \mathrm{~N}$ pràticamente não extraiu o fósforo nativo e o adicionado.

Os dados obtidos apresentam importância no estabelecimento de técnicas utilizadas em análises de solos para fins de fertilidade.

\section{INTRODUÇÃO}

Há muito que se sabe que a quantidade de fósforo, na forma de íon fosfato, extraida do solo varia de acordo com a natureza do solo e da solução extratora, com a relação entre o peso do solo e

* Entregue para publicação em 29-12-1971.

** Departamento de Química da E.S.A. "Luiz de Queiroz", USP.

*** Bolsista da Fundação de Amparo a Pesquisa do E. S. Paulo. 
o volume da solução extratora, com o tempo de contato da solução com o solo, com a técnica ou condições da extração, como agitação, percolação, etc., com a temperatura da solução e com outros fatores (BINGHAM, 1962; CATANI, NASCIMENTO \& GALLO, 1957 ; CATANI \& PELLEGRINO, 1957; OLSEN \& DEAN, 1965; LARSEN, 1967; THOMAS, 1967; MURRMANN \& PEECH, 1969). É evidente que, fazendo-se variar apenas a natureza da solução extratora, isto é, fixando-se todas as outras condições, a quantidade de fósforo solubilizada será uma função da capacidade da solução ou do soluto empregado. Por outro lado, adotando-se uma determinada solução extratora e fazendo-se variar apenas a proporção de peso da amostra para volume da solução extratora, obtêm-se dados que permitam estabelecer curvas elucidativas do processo extrativo.

Levando-se em conta que durante a agitação do solo com a solução extratora, ocorrem dois fenômenos simultâneos e opostos - solubilização do fosfato e refixação ou readsorção pelo solo as condições mais adequadas da extração do mencionado ânion só podem ser estabelecidas através de um estudo, que contemple as diversas condições citadas.

Como os solos do Estado de S. Paulo apresentam elevada capacidade de adsorção ou fixação de fósforo (CATANI \& GLÓRIA, 1964 ; NAKAMURA, 1970), tudo leva a crer que o fenômeno de refixação ou readsorção de fosfato durante o processo de extração seja apreciável.

O presente trabalho tem por objetivo o estudo da solubilização do fósforo nativo e do adicionado, através de diversas soluções e em várias proporções de peso de solo para volume de solução extratora.

As soluções extratoras utilizadas foram: $\mathrm{H}_{2} \mathrm{SO}_{4}$ 0,05 N (CATANI, GALLO \& GARGANTINI, 1955); HC1 0,05 N' $\mathrm{N}_{2} \mathrm{SO}_{4} 0,025 \mathrm{~N}$, (Melich, citado por NELSON, MEHLICH \& WINTERS, 1953) $\mathrm{H}_{2} \mathrm{SO}_{4}$ $0,05 \mathrm{~N}+\mathrm{NH}_{4} \mathrm{~F} 0,025 \mathrm{~N}$ (CATANI, NASCIMENTO \& GALLO) e ácido acético, $\mathrm{CH}_{3} \mathrm{COOH}, 0,10 \mathrm{~N}$.

\section{MATERIAL E MÉTODOS}

\section{Material}

A descrição geral, as características físicas e químicas das amostras de solos, que constituem o material do presente trabalho, constam dos quadros 1, 2, 3 e 4 .

A análise granulométrica bem como a classificação textural das diversas amostras de solos foram feitas no Centro de Estudos de Solos da Escola Superior de Agricultura "Luiz de Queiroz". 
Os métodos utilizados para a determinação dos teores de $\mathrm{Ca}+\mathrm{Mg}$ e Al3+ foram os descritos por ZUÑIGA \& CATANI (1967).

QUADRO 1 - Classificação das amostras de solos ao nível de Grande Grupo (COMISSÃO DE SOLOS, 1960).

\begin{tabular}{|c|c|c|}
\hline \multicolumn{2}{|c|}{ Amostras n. } & Grande Grupo \\
\hline & 1 & Latosol roxo (LR) \\
\hline & 2 & Podzolizado Vervelho Amarelo-orto (PV) \\
\hline & 3 & Latosol Vermelho Amarelo, face arenosa (LVa) \\
\hline & 4 & Podzolizado Lins-Marília, variação Marília (Pml) \\
\hline \multicolumn{3}{|c|}{ QUADRO 2 - Características físicas das amostras de solos. } \\
\hline $\begin{array}{c}\text { Amostras } \\
\mathrm{N}^{\circ}\end{array}$ & Horizonte & Classe texturla \\
\hline 1 & Ap & argila \\
\hline 2. & Ap & argila \\
\hline 3 & Ap & barro argiloso \\
\hline 4 & Ap & areia barrenta \\
\hline
\end{tabular}

QUADRO 3-Principais características químicas das amostras de solos.

\begin{tabular}{ccccccc}
\hline \multirow{2}{*}{$\begin{array}{c}\text { Amostras } \\
\mathrm{N}^{\circ}\end{array}$} & $\mathrm{pH}$ & \multicolumn{5}{c}{ em equivalentes miligramas/100 g solo } \\
\cline { 3 - 7 } & $(1: 2,5)$ & $\mathrm{Ca}+\mathrm{Mg}^{*}$ & $\mathrm{Al}^{3+*}$ & $\mathrm{~K}{ }^{+* * *}$ & $\mathrm{PO}_{4}^{3-* * *}$ & $\mathrm{H}^{+{ }^{* * *}}$ \\
\hline 1 & 5,70 & 4,95 & $\operatorname{tr}$ & 0,72 & 0,12 & 4,24 \\
2 & 5,45 & 2,15 & 0,75 & 0,15 & 0,03 & 6,00 \\
3 & 4,80 & 0,40 & 0,48 & 0,05 & 0,02 & 2,45 \\
4 & 7,10 & 5,05 & $\operatorname{tr}$ & 0,13 & 0,22 & 1,64 \\
\hline
\end{tabular}

* Em extratos obtidos com solução normal de KC1 (ZUÑICA \&. CATANI, 1967).

** Hidrogênio extraido com solução $1 \mathrm{~N}$ de acetado de cálcio com pH = 7,0 (0ATANI \& ALONSO 1969).

$* * *$ Extraidos com solução de $\mathrm{H}_{2} \mathrm{SO}_{4} 0,05$ normal. 
QUADRO 4 - Teores de sesquióxidos e de sílica.

\begin{tabular}{rrrr}
\hline Amostras N.' & $\mathrm{Fe}_{2} \mathrm{O}_{3} \%$ & $\mathrm{Al}_{2} \mathrm{O}_{3} \%$ & $\mathrm{SiO}_{2} \%$ \\
\hline 1 & 12,80 & 12,95 & 62,80 \\
2 & 4,80 & 13,70 & 68,50 \\
3 & 7,04 & 11,46 & 72,68 \\
4 & 2,24 & 2,38 & 90,08 \\
\hline
\end{tabular}

\section{Métodos}

\section{Reativos}

a) Solução de ácido sulfúrico 0,0714 N. Preparada por diluição a partir de uma solução padronizada $1 \mathrm{~N}$.

b) Solução sulfo-bismuto molíbdica. Setenta e cinco $\mathrm{ml}$ de $\mathrm{H}_{2} \mathrm{SO}_{4}$ foram diluidos, aos poucos, em $200 \mathrm{ml}$ de água destilada e depois de esfriar, foi adicionado $1 \mathrm{~g}$ de sub-carbonato de bismuto, agitando-se a solução. Em outro copo, foram dissolvidos $10 \mathrm{~g}$ de molibdato de amônio aos poucos, em $200 \mathrm{ml}$ de água destilada a $80-90^{\circ} \mathrm{C}$. Após o resfriamento, as duas soluções foram reunidas num balão de $500 \mathrm{ml}$ e o volume completado com água destilada.

c) Solução padrão "estoque" de fosfato monocálcico $0,10 \mathrm{~N}$. Foram transferidos $4,2015 \mathrm{~g}$ de fosfato monocálcico monohidratado $\mathrm{Ca}\left(\mathrm{H}_{2} \mathrm{PO}_{4}\right)_{2} \cdot \mathrm{H}_{2} \mathrm{O}$ para balão de 1 litro contendo mais ou menos $400-500 \mathrm{ml}$ de água destilada. Após a agitação e completa dissolução, o volume foi completado com água destilada.

d) Solução padrão "de uso" de fosfato. A partir da solução "estoque" foram preparadas as soluções padrões de fosfato, contendo $0,25-0,50-1,00-2,00-3,00-4,00-5,00-10,00$ e 20,00 equivalentes - microgramas de fosfato por mililitro.

e) Solução de ácido ascórbico a 3\%. Foram transferidos $0,750 \mathrm{~g}$ de ácido ascórbico para um balão volumétrico de $25 \mathrm{ml}$. Dissolveu-se com água destilada e o volume foi completado.

f) Solução de fluoreto de amônio normal. Foram pesados 18,5 $\mathrm{g}$ de fluoreto de amônio e dissolvidos em 200-300 ml de água destilada; transferiu-se a solução para balão de $500 \mathrm{ml}$ e o volume completado com água destilada.

g) Solução 0,0714 normal de ácido sulfúrico e 0,0357 normal em fluoreto de amônio. Foram transferidos $71,5 \mathrm{ml}$ de solução 1 normal de ácido sulfúrico e $35,7 \mathrm{ml}$ de solução normal de fluoreto de amônio para balão de 1 litro; agitou-se, completou-se o volume com água destilada e transferiu-se para recipiente de plástico. 
h) Solução 0,0714 normal em ácido clorídrico e 0,0357 normal em ácido sulfúrico. Preparada por diluição a partir de soluções padronizadas mais concentradas.

i) Solução de ácido acético 0,143 N. Preparada a partir de uma solução padronizada mais concentrada.

j) Solução de ácido bórico a 4\%. Foram transferidos $40 \mathrm{~g}$ de ácido bórico para um copo de $800 \mathrm{ml}$ contendo $600-700 \mathrm{ml}$ de água destilada; aqueceu-se a solução e após a completa dissolução, esperou-se esfriar e o volume foi completado a 1 litro.

Estabelecimento da curva padrão. Transferiu-se $1 \mathrm{ml}$ de soluções padrões contendo $0,25-0,50-1,0-2,0-3,0-4,0-$ 5,0 equivalentes microgramas de $\mathrm{PO}_{4}^{3-}$, para balões volumétricos de $50 \mathrm{ml}$. Reservou-se paralelamente um balão volumétrico de $50 \mathrm{ml}$ para prova em branco, que não recebeu solução padrão de fosfato. Foram adicionados $40 \mathrm{ml}$ de solução de $\mathrm{H}_{2} \mathrm{SO}_{4} 0,05 \mathrm{~N}$; ou $40 \mathrm{ml}$ de solução $0,05 \mathrm{~N}$ em $\mathrm{HCl}$ e $0,025 \mathrm{~N}$ em $\mathrm{H}_{2} \mathrm{SO}_{4}$; ou $40 \mathrm{ml}$ de solução de $\mathrm{H}_{2} \mathrm{SO}_{4} 0,05 \cdot \mathrm{N}$ e $0,025 \mathrm{~N}$ em $\mathrm{NH}_{4} \mathrm{~F}$; ou $40 \mathrm{ml}$ de solução de ácido acético $0,010 \mathrm{~N}$. Quando a solução extratora continha $\mathrm{NH}_{4} \mathrm{~F}$ adicionaram-se $2,5 \mathrm{ml}$ de solução de ácido bórico a 4\% (para eliminar a ação de $\mathrm{F}^{-}$). Em seguida, em todos os casos foram adicionados $5 \mathrm{ml}$ de reativo sulfo-bismuto molíbdico e $1 \mathrm{ml}$ de solução de ácido ascórbico a 3\%, agitando-se após a adição de cada reativo. $\mathrm{O}$ volume foi completado com água destilada, as soluções homogeneizadas e, após 15 minutos, foram executadas as leituras no colorímetro Lange modelo J, com filtro vermelho (620-640 milimicrons de comprimento de onda). Foram estabelecida 4 curvas e as respectivas equações de regressão.

\section{Extração do fósforo das amostras de solos}

A - Extração do fósforo nativo e do adicionado ao solo com $100 \mathrm{ml}$ de solução de ácido sulfúrico 0,05 normal.

\section{Procedimento :}

a - Foram transferidos 4 vezes, 5, 10 e $20 \mathrm{~g}$ de cada amostra de solo para frascos de Erlenmeyer de $300 \mathrm{ml}$.

$\mathrm{b}$ - Em 3 das 4 amostras de $5 \mathrm{~g}$, foi adicionado $1 \mathrm{ml}$ de cada solução padrão de fosfato monocálcico contendo, respectivamente, 5,10 e 20 equivalentes microgramas de fosfato. Uma das 4 amostras foi reservada para a extração do fósforo nativo, isto é, que não recebeu solução de fosfato. Adicionou-se, em seguida, água destilada em quantidade suficiente para que todas as amostras ficassem com um volume total de $3 \mathrm{ml}$.

c - Em 3 das 4 amostras de $10 \mathrm{~g}$, foi adicionado um volume 
de solução padrão de fosfato monocálcico a fim de fornecer, respectivamente, 10,20 e 40 equivalentes microgramas de fosfato completando-se o volume de líquido a $6 \mathrm{ml}$ de água destilada em todas as amostras. Reservou-se uma das amostras para a extração do fósforo nativo.

$\mathrm{d}$ - Em 3 das 4 amostras de $20 \mathrm{~g}$, foi adicionado um volume de solução padrão de fosfato monocálcico a fim de fornecer, respectivamente, 20,40 e 80 equivalentes microgramas de fosfato, completando-se o volume líquido a $12 \mathrm{ml}$, com água destilada em todas as amostras. Reservou-se uma das amostras para extração do fósforo nativo.

e - As amostras foram deixadas em repouso durante 4 dias.

$\mathrm{f}$ - Após o repouso, foram adicionados $70 \mathrm{ml}$ de solução de ácido sulfúrico 0,0714 normal, que correspondem a 5 equivalentes miligramas de hidrogênio, a todas as amostras e os volumes foram completados a $100 \mathrm{ml}$ com água destilada.

$\mathrm{g}$ - Procedeu-se a agitação em agitador mecânico durante 15 minutos e depois as soluções foram filtradas, através de papel Whatman n..$^{\circ}$ 1, para outros frascos de Erlenmeyer.

$\mathrm{h}$ - Dos filtrados, foram transferidas alíquotas convenientes, para balões de $50 \mathrm{ml}$ (para alíquotas menores de $40 \mathrm{ml}$, este volume foi completado com a solução extratora).

i - Foram adicionados a cada balão, $5 \mathrm{ml}$ de solução sulfobismuto molíbdica e $1 \mathrm{ml}$ de ácido ascórbico a 3\% e, após a homogeneização, os volumes foram completados a $50 \mathrm{ml}$ com água destilada. Reservou-se paralelamente um balão de $50 \mathrm{ml}$ (que constituiu a prova em branco) que recebeu $28 \mathrm{ml}$ de solução de ácido sulfúrico $0,0714 \mathrm{~N}, 5 \mathrm{ml}$ de reativo sulfo-bismuto molíbdico, $1 \mathrm{ml}$ de ácido ascórbico e o volume foi completado a $50 \mathrm{ml}$, com água destilada.

$\mathrm{j}$ - As soluções foram deixadas em repouso durante $15 \mathrm{minu}-$ tos e a seguir foram efetuadas as leituras contra a prova em branco, no colorímetro Lange com filtro vermelho $(620-640 \mathrm{~mm}$ de comprimento de onda).

$\mathrm{k}$ - As leituras obtidas foram convertidas em absorbância e a quantidade de fósforo existente nosi extratos foi calculada mediante a equação de regressão já estabelecida.

B - Extração do fósforo nativo e do adicionado ao solo com $100 \mathrm{ml}$ de solução de ácido clorídrico 0,05 $\mathrm{N}$ e ácido sulfúrico 0,025 $\mathrm{N}$.

\section{Procedimento:}

O tratamento das amostras com solução de fosfato foi o mesmo descrito para o caso da extração com ácido sulfúrico $0,05 \mathrm{~N}$. 
Para extração do fósforo nativo e do adicionado ao solo foram introduzidos $70 \mathrm{ml}$ de solução $0,0714 \mathrm{~N}$ em ácido clorídrico e 0,0357. N em ácido sulfúrico e os volumes foram completados a $100 \mathrm{ml}$ com água destilada.

C - Extração do fósforo nativo e do adicionado ao solo com $100 \mathrm{ml}$ de solução de ácido sulfúrico $0,05 \mathrm{~N}$ e fluoreto de amônio $0,025 \mathrm{~N}$.

\section{Procedimento:}

Foi seguido o mesmo procedimento dos casos anteriores, isto é, para extração do fósforo nativo e do adicionado ao solo, foram adicionados $70 \mathrm{ml}$ de solução de ácido sulfúrico $0,0714 \mathrm{~N}$ e o fluoreto de amônio $0,0357 \mathrm{~N}$ e os volumes completados a $100 \mathrm{ml}$ com água destilada. Dos extratos filtrados foram tomadas alíquotas convenientes e transferidas para balões de $50 \mathrm{ml}$. Adicionaram-se $2,5 \mathrm{ml}$ de solução de ácido bórico a 4\% para eliminação do excesso de fluoreto. Posteriormente foram adicionados $5 \mathrm{ml}$ de reativo sulfobismuto molíbdico, $1 \mathrm{ml}$ de ácido ascórbico a 3\% e o volume completado a $50 \mathrm{ml}$ com água destilada.

D - Extração do fósforo nativo e do adicionado ao solo com $100 \mathrm{ml}$ de solução de ácido acético $0,10 \mathrm{~N}$.

\section{Procedimento :}

Seguiu-se o mesmo procedimento dos casos anteriores e a extração foi feita com $70 \mathrm{ml}$ de solução de ácido acético $0,143 \mathrm{~N}$, os volumes completados a $100 \mathrm{ml}$ com água destilada. A seguir foi procedida a mesma técnica descrita para os casos de extração com solução ácido sulfúrico $0,05 \mathrm{~N}$ e com solução de ácido clorídrico $0,05 \mathrm{~N}$ e ácido sulfúrico 0,025 .

\section{RESULTADOS OBTIDOS E DISCUSSÃO}

Os resultados obtidos referentes à extração do fósforo nativo são apresentados no quadro 5.

Os dados do quadro 5 esclarecem que quando o valor da relação solo: solução variou de 5:100 para $20: 100$ a capacidade de extração de fósforo das soluções diminuiu consideràvelmente. A diminuição foi mais acentuada nos solos Latosol roxo (LR) e Padzolizado Vermelho Amerelo-orto (PV) e Latosol Vermelho Amarelo, fase arenosa (LVa). No solo Podzolizado Lins e Marília, variação Marília, o decréscimo na extração do fósforo com o aumento da relação solo: solução foi menor. Êste fato talvez seja explicável pelo baixo teor de sesquióxidos e pelo alto valor do $\mathrm{pH}$ e do teor de cálcio mais magnésio, que dariam ao fósforo uma tendência menos pronunciada de se ligar ao ferro e alumínio, do que nos demais solos. 
Quanto à capacidade de extração das diversas soluções, conservando-se constante a relação solo: volume de solução, pode-se dizer que as duas soluções de $\mathrm{H}_{2} \mathrm{SO}_{4} 0,05 \mathrm{~N}$ e a $0,05 \mathrm{~N}$ em HC1 e $0,025 \mathrm{~N}$ $\mathrm{H}_{2} \mathrm{SO}_{4}$, apresentaram-se equivalentes. A solução $0,05 \mathrm{~N} \mathrm{em} \mathrm{H}_{2} \mathrm{SO}_{4} \mathrm{e}$ $0,025 \mathrm{~N}$ em $\mathrm{NH}_{4} \mathrm{~F}$ extraiu mais fósforo do que as duas anteriores nos solos LR, PV e LVa, indicando que o ânion fluoreto (F-) favorece a extração do fósforo de solos com um teor apreciável de sesquióxidos. Esse fenômeno, já constatado em trabalhos anteriores CATANI, NASCIMENTO \& GALLO, 1957; CATANI \& PELLEGRINO, 1957), poderia ser explicado quer pela ação complexante do ânion fluoreto frente ao ferro e alumínio, liberando o ânion fosfato, quer pela troca do ânion fluoreto com fosfato do solo. No caso do solo Podzolizado Lins e Marília (Pml), variação Marília, as diferenças na extração de fósforo pela solução de ácido sulfúrico contendo fluoreto e as soluções de $\mathrm{H}_{2} \mathrm{SO}_{4}$ e de $\mathrm{HC}$ - e de $\mathrm{HC} 1+\mathrm{H}_{2} \mathrm{SO}_{4}$ foram muito pequenas, ou mesmo, pràticamente não ocorreram. A explicação do fato poderia encontrar apoio também na composição do solo em aprêço, isto é, baixo teor de sesquióxidos, alto $\mathrm{pH}$ e relativamente alto teor de cálcio mais magnésio.

QUADRO 5 - Variação da quantidade de fosfato nativo extraído do solo, em função da natureza da solução extratora e da proporção entre o peso (em gramas) de amostras de solo e o volume (em $\mathrm{ml}$ ) de soluçãó extratora.

\begin{tabular}{|c|c|c|c|c|c|}
\hline \multirow{2}{*}{ Solo } & \multirow{2}{*}{$\begin{array}{c}\text { Relação } \\
\text { Solo } \\
\text { Solução }\end{array}$} & $\mathrm{H}_{2} \mathrm{SO}_{4} \quad 0,05 \mathrm{~N}$ & $\begin{array}{cc}\mathrm{HC} 1 & 0,05 \mathrm{~N} \\
\mathrm{H}_{2} \mathrm{SO}_{4} & 0,025 \mathrm{~N} \\
\end{array}$ & $\begin{array}{l}\mathrm{H}_{2} \mathrm{SO}_{4} \quad 0,05 \mathrm{~N} \\
\mathrm{NH}_{4} \mathrm{~F} \quad 0,025 \mathrm{~N}\end{array}$ & $\mathrm{CH}_{3} \mathrm{COOH} \quad 0,10 \mathrm{~N}$ \\
\hline & & $\begin{array}{c}\mathrm{e} . \mathrm{mg} \\
\mathrm{PO}_{4}^{3-} / 100 \mathrm{~g}\end{array}$ & $\begin{array}{c}\mathrm{e} . \mathrm{mg} \\
\mathrm{PO}_{4}^{3-} / 100 \mathrm{~g} \\
\end{array}$ & $\begin{array}{c}\text { e. } \mathrm{mg} \\
\mathrm{PO}_{4}^{3-} / 100 \mathrm{~g}\end{array}$ & $\begin{array}{c}\text { e. } \mathrm{mg} \\
\mathrm{PO}_{4}^{3-} / 100 \mathrm{~g}\end{array}$ \\
\hline LR & $5: 100$ & 0,103 & 0,088 & 0,174 & $\operatorname{tr}$ \\
\hline LR & $10: 100$ & 0,072 & 0,062 & 0,127 & $\operatorname{tr}$ \\
\hline LR & $20: 100$ & 0,037 & 0,041 & 0,067 & 0,002 \\
\hline PV & $5: 100$ & 0,020 & 0,027 & 0,053 & $\operatorname{tr}$ \\
\hline PV & $10: 100$ & 0,019 & 0,021 & 0,031 & $\operatorname{tr}$ \\
\hline PV & $20: 100$ & 0,012 & 0,013 & 0,017 & $\operatorname{tr}$ \\
\hline LVa & $5: 100$ & 0,017 & 0,017 & 0,083 & $\operatorname{tr}$ \\
\hline LVa & $10: 100$ & 0,011 & 0,009 & 0,044 & $\operatorname{tr}$ \\
\hline LVa & $20: 100$ & 0,006 & 0,006 & 0,013 & $\operatorname{tr}$ \\
\hline Pml & $5: 100$ & 0,234 & 0,240 & 0,236 & 0,179 \\
\hline Pml & $10: 100$ & 0,219 & 0,219 & 0,255 & 0,165 \\
\hline Pml & $20: 100$ & 0,204 & 0,204 & 0,224 & 0,123 \\
\hline
\end{tabular}

Finalmente, em relação a extração do fósforo nativo, é conveniente examinar os dados obtidos com solução de ácido acético $0,10 \mathrm{~N}$. 
Sòmente o solo $(\mathrm{Pml})$ permitiu a extração de fósforo em quantidade determinável, enquanto os demais solos, forneceram apenas traços de fósforo. A explicação para o fenômeno em questão poderia fundamentar-se na ação solubilizante do ácido acético em relação aos fosfatos integrando sistemas cálcidos e com $\mathrm{pH}$ elevado (6,5 ou mais). Por outro lado, o ácido acético não apresenta capacidade de solubilizar o ânion fosfato quando o mesmo pertence a sistemas em que predominam os sesquióxidos e com pH baixo (5,8 ou menos), o que explicaria a baixa etração dos fósforo nos demais solos.

Os dados concernentes à extração do fósforo adicionado às amostras de solos estudados, com diversas soluções e em diferentes proporções de solo : volume de solução, são apresentados nos quadros n.os $6,7,8$ e 9.

Os dados do quadro 6 evidenciam que a extração do fósforo adicionado ao solo, com a solução de $\mathrm{H}_{2} \mathrm{SO}_{4} 0,05 \mathrm{~N}$ decresceu pronunciadamente com o aumento de relação pêso da amostra: volume da solução. Pode-se perceber de um modo mais nítido o que foi afirmado através dos dados das colunas "\% Solubilização", isto é, a porcenta-

gem de fósforo solubilizadora, calculada em função da quantidade adicionada. Verifica-se que para os solos LR, PV e PVa, a \% de solubilização do fósforo adicionado decresceu em $50 \%$ ou mais quando a proporção solo; solução cresceu de 5:100 20:100. Para o solo Podzolizado Lins e Marília, variação Marília, houve também um decréscimo, mas inferior aos ocorridos com os outros solos.

Vê-se também que quando a quantidade de fósforo adicionado cresceu, a quantidade extraída cresceu proporcionalmente, mantendo porém, a \% de soluzilização.

Os dados do quadro 7 mostram que a extração com a solução 0,05 $\mathrm{N}$ em $\mathrm{HC} 1$ e $0,25 \mathrm{~N}$ em $\mathrm{H}_{2} \mathrm{SO}_{4}$ seguiram a mesma linha geral da solução anterior $\left(\mathrm{H}_{2} \mathrm{SO}_{4} 0,05 \mathrm{~N}\right)$.

Os dados do quadro 8 confirmam a influência da relação pêso da amostra: volume da solução, sôbre a solubilização do fósforo adicio-

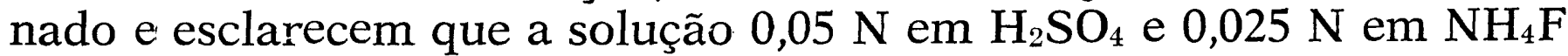
extraiu muito mais fósforo adicionado, do que as duas soluções anteriores, para os solos LR, PV e LVa. Confirma-se portanto, que nos solos ácidos, com um certo teor em sesquióxidos, o ânion fluoreto aumenta a capacidade de extração das soluções que o contém, pelas razões já apontadas. Entretanto, no solo Pml, a solução que contém fluoreto extraiu menos fósforo que as duas anteriores. Como nesse solo o teor de sesquióxidos é baixo, o pH é 7,10 e o teor de cálcio mais magnésio é razoável, o ânion fluoreto só pode prejudicar a extração do fósforo pelo efeito tampão exercído sobre a solução extratora. 
QUADRO 6 - Variação da quantidade de fosfato extraida do solo em função da quantidade adicionada e da proporção entre o peso (grama) da amostra e o volume $(\mathrm{ml})$ da solução de $\mathrm{H}_{2} \mathrm{SO}_{4} 0,05 \mathrm{~N}$.

\begin{tabular}{|c|c|c|c|c|c|c|}
\hline \multirow{4}{*}{$\begin{array}{c}\begin{array}{c}\text { Fosfato } \\
\text { adicionado } \\
\text { e. } \mathrm{mg} \mathrm{PO}^{3-} \\
100 \mathrm{~g} \mathrm{de} \\
\text { solo }\end{array} \\
\begin{array}{c}4 \\
\text { solo }\end{array}\end{array}$} & \multicolumn{6}{|c|}{ Fosfato extraído } \\
\hline & \multicolumn{6}{|c|}{ Proporção solo: volume, na extração } \\
\hline & \multicolumn{2}{|c|}{$5: 100$} & \multicolumn{2}{|c|}{$10: 100$} & \multicolumn{2}{|c|}{$20: 100$} \\
\hline & PO ${ }_{4}^{\text {e. }} \mathrm{mg}$ & $\begin{array}{l}\text { \% Solubi- } \\
\text { lização }\end{array}$ & $\begin{array}{c}\text { e. } \mathrm{mg} \\
\mathrm{PO}{ }_{4}^{3-} / 100 \mathrm{~g}\end{array}$ & $\begin{array}{l}\% \text { Solubi } \\
\text { lizaçãao }\end{array}$ & $\begin{array}{c}\text { e. } \mathrm{mg} \\
\mathrm{PO}{ }_{4}^{3-} / 100 \mathrm{~g}\end{array}$ & $\underset{\text { lização }}{\% \text { Solubi- }}$ \\
\hline
\end{tabular}

Solo: Latosol roxo ( LR )

$\begin{array}{lllllll}0,100 & 0,036 & 36,0 & 0,024 & 24,9 & 0,016 & 16,0 \\ 0,200 & 0,076 & 38,0 & 0,051 & 25,5 & 0,031 & 15,5 \\ 0,400 & 0,153 & 38,3 & 0,114 & 28,5 & 0,069 & 17,3\end{array}$

Solo: Podzolizado Vermelho Amarelo-orto (PV)

$\begin{array}{lllllll}0,100 & 0,036 & 36,0 & 0,016 & 16,0 & 0,011 & 11,0 \\ 0,200 & 0,071 & 35,5 & 0,045 & 22,5 & 0,029 & 14,5 \\ 0,400 & 0,141 & 35,3 & 0,099 & 24,8 & 0,064 & 16,0\end{array}$

Solo: Latosol Vermelho Amarelo, fase arenosa (PVa)

$\begin{array}{lllllll}0,100 & 0,015 & 15,0 & 0,010 & 10,0 & 0,007 & 7,0 \\ 0,200 & 0,041 & 20,5 & 0,022 & 11,0 & 0,012 & 6,0 \\ 0,400 & 0,084 & 21,0 & 0,056 & 14,0 & 0,034 & 8,5\end{array}$

Solo: Podzolizado Lins-Marília, variação Marília (Pm1)

$\begin{array}{lllllll}0,100 & 0,093 & 93,0 & 0,078 & 78,0 & 0,056 & 56,0 \\ 0,200 & 0,174 & 87,0 & 0,163 & 81,5 & 0,130 & 65,0 \\ 0,400 & 0,309 & 77,3 & 0,300 & 75,0 & 0,277 & 69,3\end{array}$


QUADRO 7 - Variação da quantidade de fosfato extraida do solo em função da quantidade adicionada e da proporção entre o peso (grama) da amostra e o volume $(\mathrm{ml})$ de solução $0,05 \mathrm{~N}$ em $\mathrm{HC1}$ e $0,025 \mathrm{~N}$ ẹm $\mathrm{H}_{2} \mathrm{SO}_{4}$.

\begin{tabular}{|c|c|c|c|c|c|c|}
\hline \multirow{4}{*}{$\begin{array}{c}\begin{array}{c}\text { Fosfato } \\
\text { adicionado } \\
\text { 3- } \\
\text { e. mg PO } \\
\begin{array}{c}100 \mathrm{~g} \mathrm{de} \\
\text { solo }\end{array}\end{array} \\
\end{array}$} & \multicolumn{6}{|c|}{ Fosfato extraído } \\
\hline & \multicolumn{6}{|c|}{ Proporção solo: volume, na extração } \\
\hline & \multicolumn{2}{|c|}{$5: 100$} & \multicolumn{2}{|c|}{$10: 100$} & \multicolumn{2}{|c|}{$20: 100$} \\
\hline & $\begin{array}{c}\mathrm{e} . \mathrm{mg} \\
\mathrm{PO}{ }_{3-} / 100 \mathrm{~g}\end{array}$ & $\begin{array}{l}\% \text { Solubi- } \\
\text { lização }\end{array}$ & $\begin{array}{c}\mathrm{e} . \mathrm{mg}_{3-} \\
\mathrm{PO}{ }_{4}^{1 / 100 \mathrm{~g}}\end{array}$ & $\begin{array}{c}\text { \% Solubi- } \\
\text { lização }\end{array}$ & $\begin{array}{c}\text { e. mg } \\
\text { PO }{ }_{4}^{3-} / 100 \mathrm{~g}\end{array}$ & $\begin{array}{l}\text { \% Solubi- } \\
\text { lização }\end{array}$ \\
\hline \multicolumn{7}{|c|}{ Solo: Latosol roxo ( LR ) } \\
\hline 0,100 & 0,025 & 25,0 & 0,024 & 24,0 & 0,019 & 19,0 \\
\hline 0,200 & 0,071 & 35,5 & 0,056 & 28,0 & 0,037 & 18,5 \\
\hline 0,400 & 0,135 & 33,8 & 0,120 & 30,0 & 0,084 & 21,0 \\
\hline \multicolumn{7}{|c|}{ Solo: Podzolizado Vermelho Amare } \\
\hline 0,100 & 0,036 & 36,0 & 0,023 & 23,0 & 0,016 & 16,0 \\
\hline 0,200 & $0,0 \underline{1} 1$ & 40,5 & 0,053 & 26,5 & 0,038 & 19,0 \\
\hline \multirow[t]{2}{*}{0,400} & 0,156 & 20,8 & 0,116 & 29,0 & 0,083 & 20,8 \\
\hline & 0: Latosol & Vermelho & D Amarelo, & fase aren & sa (PVa) & \\
\hline 0,100 & 0,021 & 21,0 & 0,015 & 15,0 & 0,006 & 6,0 \\
\hline 0,200 & 0,036 & 18,0 & 0,028 & 14,0 & 0,014 & 7,0 \\
\hline 0,400 & 0,083 & 20,8 & 0,057 & 14,3 & 0,037 & 9,3 \\
\hline \multicolumn{7}{|c|}{ Solo: Podzolizado Lins-Marília, variação Marília (Pm1) } \\
\hline 0,100 & 0,087 & 87,0 & 0,068 & 68,0 & 0,052 & 52,0 \\
\hline 0,200 & 0,178 & 89,0 & 0,159 & 79,5 & 0,163 & 81,5 \\
\hline 0,400 & 0,334 & 83,5 & 0,330 & 82,5 & 0,315 & 78,8 \\
\hline
\end{tabular}


QUADRO 8 -- Variação da quantidade de fosfato extraida do solo em função da quantidade adicionada e da proporção entre o peso (grama) da amostra e o volume $(\mathrm{ml})$ da solução $0,05 \mathrm{~N}$ em $\mathrm{H}_{2} \mathrm{SO}_{4}$ e 0,025 em $\mathrm{NH}_{4} \mathrm{~F}$.

\begin{tabular}{|c|c|c|c|c|c|c|}
\hline \multirow{4}{*}{$\begin{array}{l}\text { Fosfato }_{\text {adicionado }} \\
\text { e. } \mathrm{mg} \mathrm{PO}^{3-} \\
100 \mathrm{~g} \mathrm{de} \\
\text { solo }\end{array}$} & \multicolumn{6}{|c|}{ Fosfato extraído } \\
\hline & \multicolumn{6}{|c|}{ Proporção solo: volume, na extração } \\
\hline & \multicolumn{2}{|c|}{$5: 100$} & \multicolumn{2}{|c|}{$10: 100$} & \multicolumn{2}{|c|}{$20: 100$} \\
\hline & $\begin{array}{c}\mathrm{e} . \mathrm{mg} \\
\mathrm{PO}_{4}^{3-} / 100 \mathrm{~g}\end{array}$ & $\begin{array}{l}\% \text { Solubi- } \\
\text { lização }\end{array}$ & $\begin{array}{c}\mathrm{e} . \mathrm{mg} \\
\mathrm{PO}{ }_{4}^{3-} / 100 \mathrm{~g}\end{array}$ & $\begin{array}{l}\text { \% Solubi- } \\
\text { lização }\end{array}$ & $\begin{array}{c}\mathrm{e}_{. \mathrm{mg}} \mathrm{mg} \\
\mathrm{PO}{ }_{4}^{3-} / 100 \mathrm{~g}\end{array}$ & $\begin{array}{c}\% \text { Solubi- } \\
\text { lização }\end{array}$ \\
\hline \multicolumn{7}{|c|}{ Solo: Latosol roxo ( LR ) } \\
\hline 0,100 & 0,050 & 50,0 & 0,036 & 36,0 & 0,020 & 20,0 \\
\hline 0,200 & 0,106 & 53,0 & 0,072 & 36,0 & 0,036 & 18,0 \\
\hline 0,400 & 0,224 & 56,0 & 0,180 & 45,0 & 0,102 & 26,0 \\
\hline \multicolumn{7}{|c|}{ Solo: Podzolizado Vermelho Amarelo-orto (PV) } \\
\hline 0,100 & 0,040 & 40,0 & 0,038 & 38,0 & 0,023 & 23,0 \\
\hline 0,200 & 0,126 & 63,0 & 0,083 & 31,5 & 0,048 & 24,0 \\
\hline \multirow[t]{2}{*}{0,400} & 0,254 & 63,5 & 0,170 & 42,5 & 0,110 & 27,5 \\
\hline & o: Latosol & Vermelho & Amarelo, & fase aren & osa (PVa) & \\
\hline 0,100 & 0,055 & 55,0 & 0,040 & 40,0 & 0,022 & 22,0 \\
\hline 0,200 & 0,106 & 53,0 & 0,089 & 44,5 & 0,047 & 23,5 \\
\hline 0,400 & 0,244 & 61,0 & 0,188 & 47,0 & 0,111 & 27,8 \\
\hline \multicolumn{7}{|c|}{ Solo: Podzolizado Lins-Marília, variação Marília (Pm1) } \\
\hline 0,100 & 0,040 & 40,0 & 0,038 & 38.0 & 0,023 & 23,0 \\
\hline 0,200 & 0,126 & 63,0 & 0,083 & 31,5 & 0,048 & 24,0 \\
\hline 0,400 & 0,254 & 63,5 & 0.170 & 42,5 & 0,110 & 27,5 \\
\hline
\end{tabular}


QUADRO 9 - Variação da quantidade de fosfato extraida do solo em função da quantidade adicionada e da proporção entre o peso (gramas) da amostra e o volume $(\mathrm{ml})$ de solução de ácido acético $0,10 \mathrm{~N}$.

\begin{tabular}{|c|c|c|c|c|c|c|}
\hline \multirow{4}{*}{$\begin{array}{c}\text { Fosfato } \\
\text { adicionado } \\
\text { e. } \mathrm{mg} \mathrm{PO}^{3-} \\
100 \mathrm{~g} \mathrm{de} \\
\text { solo }\end{array}$} & \multicolumn{6}{|c|}{ Fosfato extraído } \\
\hline & \multicolumn{6}{|c|}{ Proporção solo: volume, na extracão } \\
\hline & \multicolumn{2}{|c|}{$5: 100$} & \multicolumn{2}{|c|}{$10: 100$} & \multicolumn{2}{|c|}{$20: 100$} \\
\hline & $\begin{array}{c}\text { e. } \mathrm{mg} \\
\mathrm{PO}{ }_{4}^{3-} / 100 \mathrm{~g}\end{array}$ & $\begin{array}{c}\text { Solubi- } \\
\text { lização }\end{array}$ & $\begin{array}{c}\text { e. } \mathrm{mg} \\
\mathrm{PO}{ }_{4}^{3-} / 100 \mathrm{~g}\end{array}$ & $\begin{array}{l}\% \text { Solubi- } \\
\text { lização }\end{array}$ & $\begin{array}{c}\mathrm{e}_{4} \mathrm{mg} \\
\mathrm{PO}{ }_{4} / 100 \mathrm{~g}\end{array}$ & $\begin{array}{l}\text { \% Solubi- } \\
\text { lizaçãó }\end{array}$ \\
\hline
\end{tabular}

Solo: Latosol roxo ( $L R$ )

$\begin{array}{lllllcr}0,100 & 0,007 & 7,0 & 0,005 & 5,0 & \operatorname{tr} & \operatorname{tr} \\ 0,200 & 0,012 & 6,0 & 0,005 & 2,5 & 0,001 & 0,5 \\ 0,400 & 0,017 & 4,3 & 0,012 & 3,0 & 0,005 & , 1,3\end{array}$

Solo: Podzolizado Amarelo-orto (PV)

\begin{tabular}{lcccccc}
0,100 & $\operatorname{tr}$ & $\operatorname{tr}$ & $\operatorname{tr}$ & $\operatorname{tr}$ & $\operatorname{tr}$ & $\operatorname{tr}$ \\
0,200 & 0,007 & 3,5 & 0,003 & 1,5 & 0,003 & 1,5 \\
0,400 & 0,012 & 3,0 & 0,009 & 2,3 & 0,007 & 1,8 \\
\hline
\end{tabular}

Solo: Latosol Vermelho Amarelo, fase arenosa (PVa)

$\begin{array}{lllllll}0,100 & \operatorname{tr} & \operatorname{tr} & \operatorname{tr} & \operatorname{tr} & \operatorname{tr} & \operatorname{tr} \\ 0,200 & \operatorname{tr} & \operatorname{tr} & \operatorname{tr} & \operatorname{tr} & \operatorname{tr} & \operatorname{tr} \\ 0,400 & \operatorname{tr} & \operatorname{tr} & \operatorname{tr} & \operatorname{tr} & \operatorname{tr} & \operatorname{tr}\end{array}$

Solo: Podzolizado Lins-Marília, variação Marília (Pm1)

\begin{tabular}{lllllll}
0,100 & 0,086 & 86,0 & 0,071 & 71,0 & 0,061 & $61,0$. \\
0,200 & 0,148 & 74,0 & 0,152 & 76,0 & 0,133 & 66,5 \\
0,400 & 0,313 & 78,3 & 0,301 & 75,3 & 0,255 & 63,8 \\
\hline
\end{tabular}


Os dados do quadro 9 mostram que a solução de ácido acético $0,10 \mathrm{~N}$ pràticamente não solubilizou o fósforo adicionado aos solos LR, PV e PVa, porquanto a porcentagem máxima de fosfato solubilizado, calculada em função da quantidade adicionada, foi de 7,0\%, no solo LR. Daí, pode-se depreender que o fósforo adicionado a solos com características similares aos LR, PV e PVa, utilizados no presente experimento (teor apreciável de sesquióxidos e $\mathrm{pH}$ baixo), tende a integrar sistemas de sesquióxidos, tornando-se insolúvel em soluções de ácido acético. Por outro lado, a porcentagem de solubilização do fósforo adicionado ao solo $\mathrm{Pml}$, em solução de ácido acético $0,10 \mathrm{~N}$, foi elevada, o que confirma que nesse solo (com as características descritas ) tanto o fósforo nativo como o adicionado tendem a participar de sistemas cálcidos.

\section{CONCLUSÕES}

a) A extração do ânion fosfato nativo e do adicionado ao solo decresceu pronunciadamente quando a relação pêso da amostra: volume da solução extratora variou de 5:100 para 20:100, fato êste de importância no estabelecimento de técnicas a serem empregadas em análises de solos, para fins de fertilidade.

b) A solução de $\mathrm{H}_{2} \mathrm{SO}_{4} 0,05 \mathrm{~N}$ e a de $\mathrm{HC1} 0,05 \mathrm{~N}+\mathrm{H}_{2} \mathrm{SO}_{4}$ $0,025 \mathrm{~N}$ mostraram-se pràticamente equivalentes na extração do fósforo nativo e do adicionado às amostras de solos estudadas.

c) A solução $0,05 \mathrm{~N}$ em $\mathrm{H}_{2} \mathrm{SO}_{4}$ e $0,025 \mathrm{~N}$ em $\mathrm{NH}_{4} \mathrm{~F}$ extraiu mais fósforo nativo e adicionado do que as duas citadas no ítem $\mathbf{b}$, nos colos LR, LVa e PV, isto é, em solos com certo teor de sesquióxidos e $\mathrm{pH}$ baixo, indicando a ação solubilizante do ânion fluoreto, quer pela ação complexante frente ao ferro e alumínio, quer pelo fenômeno de troca aniônica, ou ainda, evitando a refixação ou readsorção do fósforo extraído e que se encontra em solução.

d) A solução de ácido acético $0,10 \mathrm{~N}$ pràticamente não extraiu fósforo nativo e adicionado dos solos LR, LVa e PV, indicando que nesses solos o ânion fosfato tende a integrar sistemas de sesquióxidos; por outro lado no solo $\mathrm{Pml}(\mathrm{pH}=7,1$ com baixo teor em sesquióxidos ) a solução de ácido acético $0,10 \mathrm{~N}$ extraiu um teor relativamente elevado do fósforo nativo e do adicionado, fornecendo para êste último uma elevada porcentagem de solubilização e indicando que em solos com características semelhantes, o fósforo tende a se unir a sistemas cálcicos.

\section{SUMAMRY}

\section{SOLUBILITY OF NATIVE AND ADDED SOIL PHOSPHORUS}

Native and added phosphorus were extracted from several soils samples with $0.05 \mathrm{~N} \mathrm{H}_{2} \mathrm{SO}_{4}, 0.05 \mathrm{~N} \mathrm{HC1}+0.025 \mathrm{~N} \mathrm{H}_{2} \mathrm{SO}_{4}, 0.05 \mathrm{~N}$ 
$\mathrm{H}_{2} \mathrm{SO}_{4}+0.025 \mathrm{~N} \mathrm{NH}_{4} \mathrm{~F}$ and $\mathrm{CH}_{3} \mathrm{COOH} 0.10 \mathrm{~N}$ solutions, in conjunction with three solution: soil ratio, 5:100, 10:100 and 20:100 keeping constant the lenght of extraction period for 15 minutes.

The soil solution ratio showed a marked influence on the phosphorus extraction, that is, there was a decrease of $50 \%$ or more, when the ratio varied from $5: 100$ to $20: 100$.

The $0.05 \mathrm{~N} \mathrm{H}_{2} \mathrm{SO}_{4}+0.025 \mathrm{~N} \mathrm{NH}_{4} \mathrm{~F}$ solution extracted more phosphorus than $0.05 \mathrm{~N} \mathrm{H}_{2} \mathrm{SO}_{4}$ and $0.05 \mathrm{HC} 1+0.025 \mathrm{~N} \mathrm{H}_{2} \mathrm{SO}_{4}$ solutions from the soil with pH 5.70 or less and with more than $17.0 \%$ of $\mathrm{Fe}_{2} \mathrm{O}_{3}+\mathrm{A}_{2} \mathrm{O}_{3}$. This point out that the anion $\mathrm{F}^{-}$allows a better phosphorus extraction from those soils.

The $0.10 \mathrm{~N} \mathrm{CH}_{3} \mathrm{COOH}$ solution extracted phosphorus only from the soil with $\mathrm{pH}=7.10$ and with $5.6 \%$ of $\mathrm{Fe}_{2} \mathrm{O}_{3}+\mathrm{Al}_{2} \mathrm{O}_{3}$, showing that acetic acid solution did not evtract native and added phosphorus from acid soils and with a high content of iron and or aluminium oxides.

\section{LITERATURA CITADA}

BINGHAM, F. T., 1962 - Chemical soil tests for available phosphorus. Soil Sci. 94:87-95.

CATANI, R. A., GALLO, J. R. \& GARGANTINI, H., 1955 - Amostragem de solo, métodos de análise, interpretação e indicações gerais para fins de fertilidade. S. Paulo, Instituto Agronômico de Campinas (Boletim) $6928 \mathrm{pp}$.

CATANI, R. A., NASCIMENTO, A. C. DO \& GALLO, J. R., 1957 - Formas de ocorrência do fósforo nos solos do Estado de S. Paulo. Revista de Agricultura, 32:147-163.

CATANI, R. A. \& PELLEGRINO, D., 1957 - A fixação do fósforo em alguns solos do Estado de S. Paulo, estudada com auxílio do fósforo radioativo P32. Revista de Agricultura, 32:237-252.

CATANI, R. A. \& GLÓRIA, N. A. DA, 1964 - Evaluation of the capacity of phosphorus fixation by the soil through the isotopic exchange, using $15 \mathrm{P}^{32}$. Anais da ESALQ, 21:229-237.

CATANI, R. A. \& ALONSO, O., 1969 - Avaliação da exigência de calcário do solo. Anais da EALQ, 26:141-155.

COMISSÃO DE SOLOS, 1960 - Levantamento de Reconhecimento dos Solos do Estado de São Paulo. Centro Nacional de Ensino e Pesquisas Agronômicas. Boletim n. ${ }^{\circ}$ 12. R. J. Brasil. 634 pp.

LARSEN, S., 1967 - Soil Phosphorus. Em: Advances in Agronomy. Vol. 19. Editado por A. G. Norman. Academic Press. New York. pp. 151-210.

MURRMANN, R. P. \& PEECH, M. 1969 - Effect of pH on labile and soluble phosphate in soils. Soil Sci. Soc. Amer. Proc. 33:205-210.

NAKAMURA, P. N., 1970 - A variação de fixação do fósforo em função do pH do solo. Relatórios apresentados à FAPESP (datilografados). 
NELSON, W. L., MEHLICH, A. \& WINTERS, E., 1953 - The Devolopment, Evaluation and Use of Soil. Tests for Phosphorus Availability. Em: Soil and Fertilizer Phosphorus in Crop Nutrition. Editado por W. H. Pierre \& A. G. Norman. Academic Press Inc. New York. pp. 153-183.

OLSEN, S. R. \& DEAN, L. A., 1965 - Phosphorus. Em: Methods of Soil Analysis. Parte 2. Editado por C. E. Black e outros. Amer. Soc. of Agron. Inc. Publisher. Madison. Wisconsin. pp. 1035-1049.

THOMAS, G. W., 1967 - Problema Encountered in Soil Testing Methods. Em: Soil Testing and Plant Analysis. Parte I. Soil Sci. Soc. of Amer. Inc. Publisher. Madison. Wisconsin. pp. 37-54.

ZUÑIGA, A. A. T. \& CATANI, R. A., 1967 - Extração de diversos íons do solo com solução normal de KC1. Anais da ESALQ, 24:289-313. 